\title{
GMR
}

\section{Nramp1 gene expression in different tissues of Meishan piglets from newborn to weaning}

\author{
C.H. Dai, J.Y. Wu, C.X. Zhao, L.H. Yu, W.B. Bao and S.L. Wu \\ Key Laboratory for Animal Genetics, Breeding, \\ Reproduction and Molecular Design of Jiangsu Province, \\ College of Animal Science and Technology, Yangzhou University, \\ Yangzhou, Jiangsu, China \\ Corresponding author: S.L. Wu \\ E- mail: pigbreeding@163.com
}

Genet. Mol. Res. 16 (1): gmr16019288

Received September 15, 2016

Accepted January 19, 2017

Published March 16, 2017

DOI http://dx.doi.org/10.4238/gmr16019288

Copyright $(2017$ The Authors. This is an open-access article distributed under the terms of the Creative Commons Attribution ShareAlike (CC BY-SA) 4.0 License.

ABSTRACT. Natural resistance-associated macrophage protein gene
1 (Nramp1) plays an important role in the innate immune response of
swine, and is believed to influence disease resistance. In this study, a
real-time quantitative polymerase chain reaction technique was used
to investigate Nramp1 expression in 12 different tissues in newborn
and 7-, 14-, $21-, 28-$, and 35 -day-old Meishan piglets. Results indicated
that Nramp1 was expressed to varying degrees in all sample tissues,
although expression differed among growth stages. For example,
Nramp1 was highly expressed in the spleen, but minimally expressed
in heart, liver, and muscle tissues among the various piglet age classes.
Overall, Nramp1 expression increased with age, reaching significant
levels in 21 - and 28-day-old animals. Nramp1 was expressed in all 12
tissues tested; however, expression in spleen, lung, kidney, and thymus
tissues was highest among newborns, which is consistent with this
gene's role in innate immunity improvement. Before and after weaning,
Nramp1 was highly expressed in digestive (stomach) and intestinal
(duodenum, jejunum, and ileum) tissues, further indicating a genetic

Genetics and Molecular Research 16 (1): gmr16019288 
role in both immune regulation to compensate for weaning stress and enhanced development of intestinal immunity.

Key words: Pig; Nramp1; Differential expression; Disease-resistant breeding

\section{INTRODUCTION}

Natural resistance-associated macrophage protein gene 1 (Nramp1) is a member of the Nramp family, originally discovered on chromosome 1 in mice. Nrampl encodes a phosphoglycoprotein that functions as an ion channel during molecular transport (Cellier et al., 1995; Vidal et al., 1996). It is primarily expressed by macrophages in endothelial cell organs, including peripheral blood leukocytes, and spleen and lung tissues, which affects not only autoimmunity, but also resistance to Salmonella and various other intracellular pathogenic microorganisms (Blackwell, 1996; Lam-Yuk-Tseung et al., 2006; McDermid and Prentice, 2006; Tanaka et al., 2007; Kadkhodazadeh et al., 2016). In addition, another study found that the Nrampl gene could influence Bacillus CalmetteGuérin (BCG) tuberculosis vaccine efficacy, indicating that Nramp1 plays an important immune regulation function with regard to pathogenic response (Badawy et al., 2013). Similarly, He et al. (2013) found that A24101991G of Nrampl was significantly associated with salmonellosis resistance.

In pigs, the Nrampl gene was initially cloned by Tuggle et al. (1997) and is located on chromosome 15 q23-26 (Sun et al., 1998). The $15 \mathrm{~kb}$ Nrampl gene is comprised of 15 exons and 14 introns. Many studies have shown that polymorphism of pig Nrampl is correlated with both immune function (Wu et al., 2008) and diarrhea in piglets ( $\mathrm{Gu}, 2006$; Liu et al., 2010; Zhao et al., 2013). Among indigenous Chinese pig breeds (specifically Tibetan and Huai pigs) and in hybrid boar, Nrampl gene expression exists in all tissues (Ying and Zhang, 2007; Chen and Liu, 2009; Ding et al., 2014), whereas some tissue specificity was reported in foreign pigs, in which Nrampl was not expressed in ileum, colon, or brain tissues (Zhang et al., 2000). Despite a correlation between polymorphism of Nrampl and diarrhea in piglets, and some profile variation in tissue expression data, it has not been determined whether expression of Nrampl is related to general disease resistance in piglets (nonspecific immunity). Immune regulatory functions of Nrampl in intestinal tissues (specific immunity) are also not well understood.

Piglet growth from birth to weaning is significantly affected by food changes (i.e., transition from breast milk to feed), as is immunity to disease. Because the piglets no longer receive maternal antibodies from breast milk, immune responses are easily stimulated by the external environment, and diarrhea is more likely to occur. Therefore, this study measured Nramp1 expression in various tissues from Meishan piglets at different developmental stages from newborn to weaning (ages ranging from newborn to 7-, 14-, 21-, 28- and 35-day-old), and investigated possible mechanisms for Nrampl-associated gene regulation on weaningand external pathogen-related stress. A real-time fluorescent quantitative polymerase chain reaction (qPCR) technique was used to detect Nramp1 mRNA expression levels in various tissues. The results provide a theoretical basis for further study of Nrampl function and regulatory mechanisms.

Genetics and Molecular Research 16 (1): gmr16019288 


\section{MATERIAL AND METHODS}

\section{Experimental materials and reagents}

Experimental pigs were obtained from Meishan Pig Conservation Breeding Co., Ltd. in Kunshan, Jiangsu Province, China. Six piglets from each litter were selected as experimental animals, one of which was slaughtered at each developmental stage (e.g., newborn, 7-, 14-, 21-, 28-, and 35-day-old). At the same time, five piglets with similar characteristics (e.g., size and weight) were also selected from half-sib families for slaughter experiments. Thus, five piglets were tested at each developmental stage. Twelve (12) samples were obtained from heart, lung, liver, spleen, stomach, kidney, thymus, lymph node, muscle, duodenum, jejunum, and ileum tissues, and preserved in liquid nitrogen until needed. TRIZOL reagent was purchased from Invitrogen (USA), reverse transcription (HiScript Q Select RT SuperMix for qPCR) and quantitative fluorescence (AceQ qPCR SYBR Green Master Mix) kits were both purchased from Vazyme Biotech Co., Ltd. (Nanjing, China).

\section{Primer design for qPCR}

Using Primer Express 5.0 software, an Nramp1 primer was designed according to Nrampl gene sequences found in the GenBank database (accession No. NC_010457.4), and included qPCR-crossed exons to avoid contamination of genomic DNA. The GAPDH gene was used as an internal control, and primers were synthesized by Sangon Biotech Co., Ltd. (Shanghai, China). Primer information is shown in Table 1.

Table 1. Primers used for real-time PCR.

\begin{tabular}{l|l|c|c}
\hline Gene & Primer sequence $\left(5^{\prime} \rightarrow 3^{\prime}\right)$ & Product length & GenBank accession No. \\
\hline \multirow{2}{*}{ Nramp1 } & F: GTGAGGACAGCCAAGTTGAG & NC_010457.4 \\
\cline { 2 - 2 } & R: TCTCCTCCTGCTCCAATCCAG & & \\
\hline \multirow{2}{*}{ GAPDH } & F: CATCATCCCTGCTTCTACTGG & & $187 \mathrm{bp}$ \\
\cline { 2 - 4 } & R: TCTCCTCCTGCTCCAATCCAG & & NC_010447.4 \\
\hline
\end{tabular}

\section{Total RNA extraction and qPCR amplification}

The TRIZOL method was used to extract total RNA from all tissue samples in strict accordance with TRIZOL reagent manual protocols. Total RNA was visualized using $1 \%$ formaldehyde denaturing agarose gel electrophoresis, and RNA concentration and urity were measured using a NanoDrop ND-1000 nucleic acid/protein concentration meter (GE, USA). RNA was frozen and stored at $-70^{\circ} \mathrm{C}$ until needed. cDNA was synthesized using RNA as a template in $10 \mu \mathrm{L}$ reactions containing $2 \mu \mathrm{L} 5 \mathrm{x}$ qRT SuperMix II and $500 \mathrm{ng}$ total RNA, with the volume made up of RNase-free $\mathrm{ddH}_{2} \mathrm{O}$. Cycling parameters were $25^{\circ} \mathrm{C}$ for $10 \mathrm{~min}, 50^{\circ} \mathrm{C}$ for $30 \mathrm{~min}$, and $85^{\circ} \mathrm{C}$ for $5 \mathrm{~min}$. Reaction mixtures were stored at $4^{\circ} \mathrm{C}$.

Real-time fluorescent quantitative PCR experiments contained $2.0 \mu \mathrm{L}$ cDNA, $0.4 \mu \mathrm{L}$ upstream and downstream primers $(10 \mu \mathrm{M}), 10 \mu \mathrm{L} 2 \mathrm{X}$ SYBR Premix ExTaq II, and $0.4 \mu \mathrm{L}$ 50X ROX Reference Dye II, with the volume made up of $20 \mu \mathrm{L}$ RNase-free $\mathrm{ddH}_{2} \mathrm{O}$. All experiments were performed in triplicate. Cycling parameters were $95^{\circ} \mathrm{C}$ for $30 \mathrm{~s}, 95^{\circ} \mathrm{C}$ for $5 \mathrm{~s}$, and $60^{\circ} \mathrm{C}$ for $34 \mathrm{~s}$, for 40 total cycles. To analyze the specificity of amplification

Genetics and Molecular Research 16 (1): gmr16019288 
products, samples were collected at the end of the PCR amplification process for melting curve determination, and were subjected to thermal cycling at $95^{\circ} \mathrm{C}$ for $15 \mathrm{~s}, 60^{\circ} \mathrm{C}$ for $1 \mathrm{~min}$, $95^{\circ} \mathrm{C}$ for $15 \mathrm{~s}$, and $60^{\circ} \mathrm{C}$ for $15 \mathrm{~s}$.

\section{Statistical analysis}

Relative quantitative results were analyzed using the $2^{-\Delta \Delta C}$ method (Livak and Schmittgen, 2001). Significant differences in Nrampl expression among various tissues at different developmental stages were determined using the general linear model (GLM) multivariate statistical method in SPSS17.0 software. Data are reported as means \pm standard deviation.

\section{RESULTS}

\section{Determination of total RNA integrity and purity}

The results of $1 \%$ formaldehyde denaturing agarose gel electrophoresis following RNA extraction (Figure S1) revealed three RNA bands (28S, 18S, and 5S), with no obvious degradation or DNA contamination. The RNA A260/A280 ratio of RNA and protein concentration measured by NanoDrop ND-1000 was 1.8-1.9, which indicated high RNA integrity and purity, and thus, suitability for use in subsequent experiments.

\section{qPCR amplification and melting curves}

An amplification-reaction kinetics curve was plotted against cycle number, and the amount of fluorescence automatically generated by the system was subtracted from the measured fluorescence change. Amplification product specificity was judged based on the melting curve, which indicated that the Nrampl gene had been amplified successfully, with only one specific qPCR product and no primer dimers or nonspecific products (Figure S2A and S2B).

\section{Analysis of Nramp1 expression in different tissues and developmental stages}

The average expression level of Nrampl in muscle tissue taken from newborn Meishan piglets was used as a reference for comparison with expression levels in other tissues and at other developmental stages. Results indicated that Nrampl mRNA expression increased steadily with age from newborn to 28 -day-old piglets, then clearly decreased at 35 days old (Figure 1). Nrampl was expressed at relatively low levels in heart, liver, and muscle tissue, whereas the gene was expressed at relatively high levels in spleen, lung, kidney, thymus, and lymphatic tissues. This was particularly evident in spleen tissue taken from newborn, 7-, and 14-day-old piglets (Figure 2). However, expression increased significantly in stomach tissue, and clearly increased in intestinal tissue, at 21 days old. By 28 days old, Nramp1 expression in stomach tissues had reached its maximum and had increased in kidney and intestinal tissues. Expression peaked in kidney tissues at 35 days old, although expression in other tissues had begun to decrease at this point.

Genetics and Molecular Research 16 (1): gmr16019288 


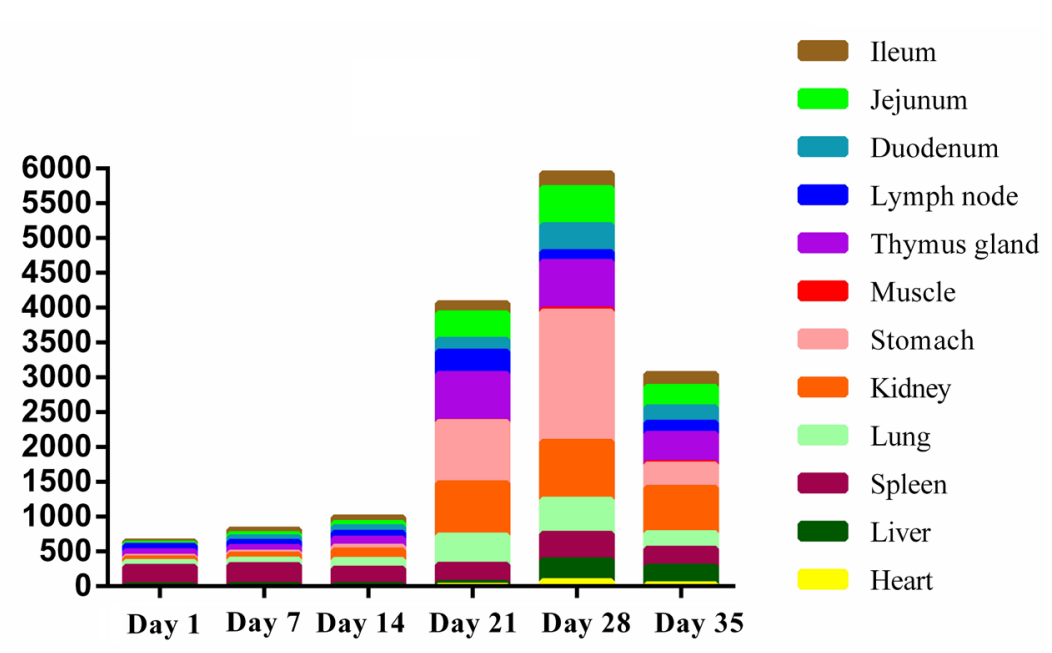

Figure 1. Overall expression of Nrampl gene in 12 different tissues in Meishan piglets at various developmental stages.

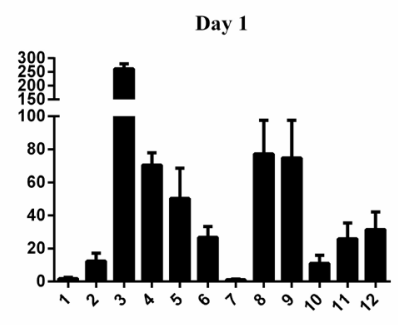

Day 21

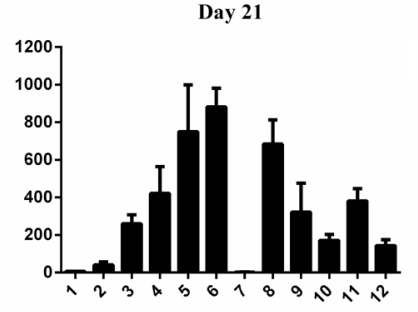

Day 7

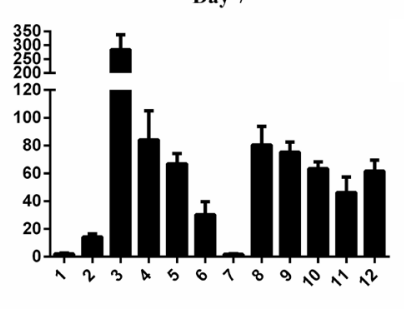

Day 28

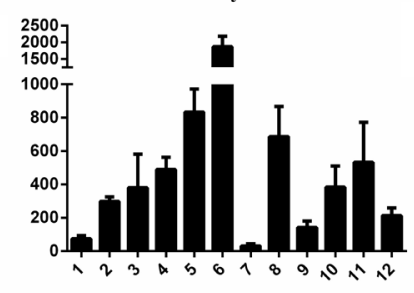

Day 14

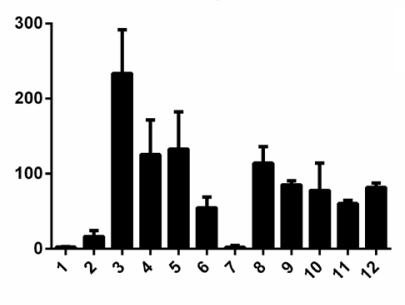

Day 35

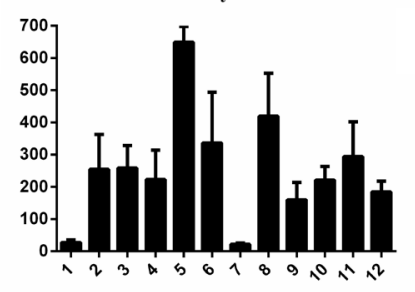

Figure 2. Expression profiles of Nrampl gene in 12 different tissues in Meishan piglets at various developmental stages. Items 1-12 represent heart, liver, spleen, lung, kidney, stomach, muscle, thymus, lymph, duodenum, jejunum, and ileum, respectively.

\section{Expression trends and difference analysis of Nramp1 gene in various tissues of Meishan piglets with increasing age}

The average expression rate of Nramp1 in muscle tissue taken from newborn Meishan piglets was used as a reference for comparison with expression levels found in nine other tissues (spleen, lung, kidney, stomach, thymus, lymph, duodenum, jejunum, and ileum) at 
various developmental stages. Expression of Nrampl in different tissues varied considerably with age (Figure 3): Nrampl expression was consistently high in spleen tissue, and reached significant levels $(\mathrm{P}<0.05)$ at 28 days old, but was down-regulated at 35 days old. Similarly, expression was also up-regulated with age in lung, kidney, stomach, duodenum, jejunum, and ileum tissues, reaching a highly significant peak $(\mathrm{P}<0.01)$ at 21 days old, then downregulated at 35 days old. Expression of Nramp1 in the thymus was up-regulated with age, reaching a highly significant peak $(\mathrm{P}<0.01)$ at 21 days old, and then decreasing at 35 days old, although levels at the latter developmental stage were still significantly higher than those at 14 days old. Expression of Nrampl in lymphatic tissue gradually increased in newborn to 21-day-old piglets, peaking at 21 days old $(\mathrm{P}<0.01)$, but was then down-regulated at 28 days old, and up-regulated again at 35 days old.
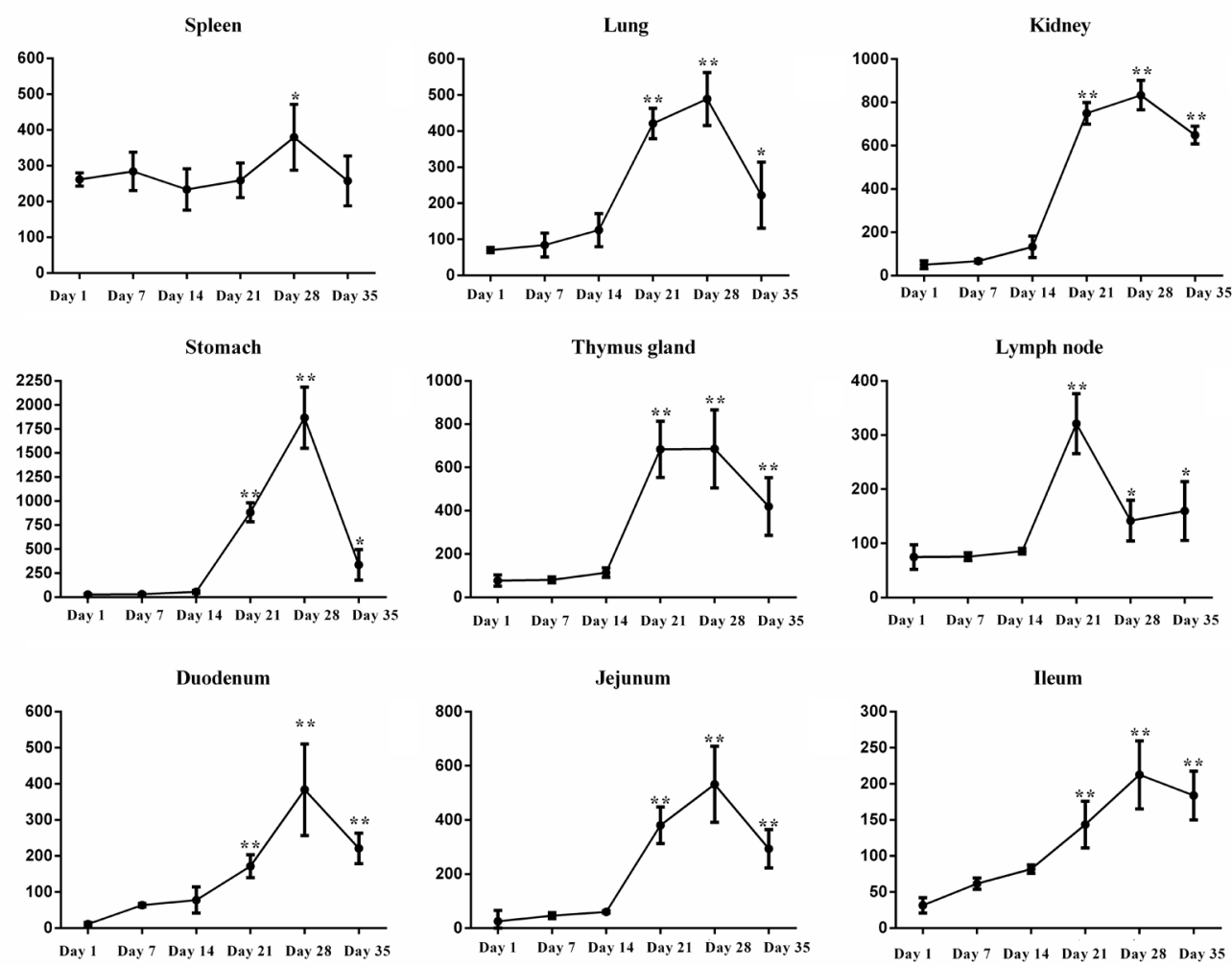

Figure 3. Trends and difference analysis of Nrampl expression in various tissues in Meishan piglets with increasing age, from newborn to weaning.

\section{DISCUSSION}

Nramp1 possesses conserved sequence elements that clearly place it in the Nramp transporter family. It serves an apparent role in host defense against microbial infection (Blackwell, 1996; Govoni and Gros, 1998; He et al., 2013), and is considered an important 
immune response-related gene (Wu et al., 2008; Chen et al., 2012; Badawy et al., 2013). Previous studies have indicated that the Nrampl protein serves a role in pathogenic infection resistance via a mechanism involving the transport of metal ions such as $\mathrm{Mn}^{2+}$ and $\mathrm{Fe}^{2+}$. Such ions are essential to the function of bacterial immune defense enzymes, and bacteria lose viability without them (Supek et al., 1996). In addition, Nramp1 can transport divalent metal ions that activate macrophages in autoimmune and a variety of other infectious diseases, thereby generating reactive oxygen species that kill microorganisms and host cells (Cellier et al., 2007). Moreover, Nrampl plays an important role in nitric oxide generation and inflammatory response (Fritsche et al., 2008).

Based on existing research, differential expressions of Nrampl in 12 tissues taken from Meishan piglets ranging in age from newborn to weaning were investigated in this study to establish a basic data profile for Nrampl tissue expression and regulation among piglet age classes. Results indicated that Nrampl was expressed in all tissues tested regardless of individual tissue specificity, although expression at different developmental stages did vary significantly. This finding was consistent with Nramp1 tissue expression among hybrid boar and indigenous Tibetan and Huai breeds, but differed from that in foreign pig breeds (Zhang et al., 2000; Ying and Zhang, 2007; Chen and Liu, 2009; Ding et al., 2014). Nramp1 was expressed at relatively high levels in the spleen, which is the largest immune response-related organ in the body that develops and produces macrophages and lymphocytes, and is key to both humoral and cellular immunity in Chinese pig breeds. It is logical, therefore, that high expression of Nrampl in spleen tissue is likely consistent with the body's capacity for immune response.

Overall, Nramp1 expression was relatively low in heart, liver, and muscle tissues, relatively high in spleen, lymph, thymus, kidney, and lung tissues, and was consistently highest in spleen tissues during the early stages of Meishan piglet development (newborn to 14 days old). During this time, the digestive tract is not fully developed as food intake consists of milk secreted by the sow. As a result, the immune system is also incomplete, and resistance to external stimulation/pathogens is mainly produced by maternal antibodies in milk and acquired via congenital immunity. High expression of Nrampl in immune tissues thus indicates a potentially important regulatory role in congenital immunity in piglets.

At 21 days old, Nrampl expression was up-regulated in both stomach and intestinal tissues. Interestingly, previous studies have shown that a sow's milk yield peaks approximately 21 days after parturition, with both yield and nutrient content diminishing after this time (Lan, 2003). Thus, piglets begin to take in exogenous feed when they are about 21 days old, at which point the stomach and intestinal tissues of their digestive organs and digestive tract suffer increased stress, and are more susceptible to invasion from external stimulation/pathogens found in food and the surrounding environment. We speculated that the high expression of Nrampl in these tissues is therefore consistent with a piglet's own immune response capability.

At 28 days old, piglets enter the early weaning stages, at which point, weaning stress becomes the primary cause of diarrhea. Because Nrampl expression significantly increased in multiple tissues at this stage, it suggested that piglets might improve their immunity to weaning stress by increasing the expression of Nramp1. Furthermore, Nramp1 expression was consistently elevated in the spleen throughout all stages of growth and development, implicating Nrampl itself as a major component in macrophage-associated resistance in endothelial organs. This result indicates that Nrampl presents a clearly defined expression trend in piglet age classes from newborn to weaning.

Genetics and Molecular Research 16 (1): gmr16019288 
In the majority of other sampled tissues, Nramp1 expression increased gradually with age, reaching significantly high levels $(\mathrm{P}<0.01)$ at 21 days old, continuing to increase at 28 days old, and then declining at 35 days old. As stated previously, piglets generally begin to consume exogenous feed at around 21 days old, and are weaned at around 28 days old, at which point they are most vulnerable to invasion by external pathogens. Before and after weaning, the body's immune response declines due to changes in feeding and the loss of maternal antibodies present in milk, thereby increasing vulnerability to intestinal bacteria and viral diarrhea in particular. High levels of Nrampl expression in immune-associated and intestinal tissues at 21 and 28 days old suggests that high levels of Nramp1 expression are associated with both non-specific and specific immunity in piglets.

Study sampling limitations included the selection of five half-sib piglets rather than full-sibs for expression differences analysis. Piglets selected represented the same growth stages, although differences in number and quality of litters were noted. In addition, only mRNA expression level (without protein expression level) analysis was performed in this study, and was not rigorous. All experimental animals used were piglets of normal phenotype without symptoms of pathological diarrhea.

Results demonstrated a close relationship between Nramp1 expression and immune response in piglets. Specific relationships between Nrampl expression and diarrhea in piglets require further study focusing on expression differences between normal and diarrhea-prone Meishan piglets, combined with susceptibility analysis for Nrampl knock-down and overexpression in individuals. The results of this study provide a platform for future research into the regulatory role of, and molecular mechanisms underpinning, the Nrampl gene, which may prove Nramp1 to be an effective molecular genetic marker.

\section{CONCLUSION}

To establish a basic data profile for Nramp1 tissue expression and expression regulation among piglet age classes, real-time quantitative PCR was used in this study to investigate Nrampl expression in 12 different tissues in newborn, 7-, 14-, 21-, 28-, and 35-day-old Meishan piglets. Results indicated that Nramp1 was expressed in all tissues to varying degrees, and was highly expressed in the spleen, but minimally expressed in heart, liver, and muscle tissues at different growth stages. Nrampl expression increased with age and reached significant levels in 21- and 28-day-old animals. In newborns, Nramp1 was expressed at the highest levels in spleen, lung, kidney, and thymus tissues. Before and after weaning, Nrampl was highly expressed in both digestive and intestinal tissues, indicating a role in immune regulation during weaning stress and in intestinal immunity in particular. The results of this study provide a platform for future research into the regulatory role of, and molecular mechanisms underpinning, Nrampl.

\section{Conflicts of interest}

The authors declare no conflict of interest.

\section{ACKNOWLEDGMENTS}

Research supported by the National Science and Technology Supporting Project of

Genetics and Molecular Research 16 (1): gmr16019288 
Jiangsu Province (\#2015BAD03B01), the Genetically Modified Organisms Technology Major Project (\#2014ZX08006-001B), and the Priority Academic Program Development (PAPD) of Jiangsu Higher Education Institutions.

\section{REFERENCES}

Badawy AA, Yahya RS, Awad SI, Al-Sawah GA, et al. (2013). Relationship between NRAMP1 gene polymorphism and efficacy of BCG vaccine in a helminth-infected population. Genet. Mol. Res. 12: 3048-3056. http://dx.doi. org/10.4238/2013.January.30.4

Blackwell JM (1996). Structure and function of the natural-resistance-associated macrophage protein (Nramp1), a candidate protein for infectious and autoimmune disease susceptibility. Mol. Med. Today 2: 205-211. http://dx.doi. org/10.1016/1357-4310(96)88773-9

Cellier M, Privé G, Belouchi A, Kwan T, et al. (1995). Nramp defines a family of membrane proteins. Proc. Natl. Acad. Sci. USA 92: 10089-10093. http://dx.doi.org/10.1073/pnas.92.22.10089

Cellier MF, Courville P and Campion C (2007). Nramp1 phagocyte intracellular metal withdrawal defense. Microbes Infect. 9: 1662-1670. http://dx.doi.org/10.1016/j.micinf.2007.09.006

Chen DK, Xie XP, Chen YF, Sun SK, et al. (2012). Advances on the disease resistance of Nramp1 gene in livestock and poultry. Anim. Husb. Feed Sci. 33: 79-81.

Chen HS and Liu D (2009). NRAMP1 gene in quantitative expression of wild boar crossbred pigs. J. Northeast Agric. Univ. 40: 75-78.

Ding X, Zhang X, Yang Y, Ding Y, et al. (2014). Polymorphism, expression of natural resistance-associated macrophage protein 1 encoding gene (NRAMP1) and its association with immune traits in pigs. Asian-australas. J. Anim. Sci. 27: 1189-1195. http://dx.doi.org/10.5713/ajas.2014.14017

Fritsche G, Nairz M, Werner ER, Barton HC, et al. (2008). Nramp1-functionality increases iNOS expression via repression of IL-10 formation. Eur. J. Immunol. 38: 3060-3067. http://dx.doi.org/10.1002/eji.200838449

Govoni G and Gros P (1998). Macrophage NRAMP1 and its role in resistance to microbial infections. Inflamm. Res. 47: 277-284. http://dx.doi.org/10.1007/s000110050330

Gu YJ (2006). Study on the relationship between NRAMP1 gene and piglet diarrhea and its production traits. Masters Thesis, Northeast Agricultural University, China.

He XM, Fang MX, Zhang ZT, Hu YS, et al. (2013). Characterization of chicken natural resistance-associated macrophage protein encoding genes (Nramp1 and Nramp2) and association with salmonellosis resistance. Genet. Mol. Res. 12: 618-630. http://dx.doi.org/10.4238/2013.January.30.5

Kadkhodazadeh M, Ebadian AR, Amid R, Zarnegarnia P, et al. (2016). Natural resistance associated macrophage protein 1 gene polymorphism is associated with chronic periodontitis not peri-implantitis in an Iranian population: a cross sectional study. Acta Med. Iran. 54: 323-329.

Lam-Yuk-Tseung S, Picard V and Gros P (2006). Identification of a tyrosine-based motif (YGSI) in the amino terminus of Nramp1 (Slc11a1) that is important for lysosomal targeting. J. Biol. Chem. 281: 31677-31688. http://dx.doi. org/10.1074/jbc.M601828200

Lan DC (2003). Introduction of piglets feeding food calling technology. Fujian J. Anim. Husb. Vet. 25: 38.

Liu YD, Xu HQ, Ji XQ, Zhang Y, et al. (2010). NRAMP1 gene polymorphism and pigs. Piglet diarrhea research. Chin. Anim. Husb. Vet. Med. 37: 125-127.

Livak KJ and Schmittgen TD (2001). Analysis of relative gene expression data using real-time quantitative PCR and the $2^{(-\Delta \Delta \mathrm{C}(\mathrm{T}))}$ Method. Methods 25: 402-408. http://dx.doi.org/10.1006/meth.2001.1262

McDermid JM and Prentice AM (2006). Iron and infection: effects of host iron status and the iron-regulatory genes haptoglobin and NRAMP1 (SLC11A1) on host-pathogen interactions in tuberculosis and HIV. Clin. Sci. 110: 503524. http://dx.doi.org/10.1042/CS20050273

Sun HS, Wang L, Rothschild MF and Tuggle CK (1998). Mapping of the natural resistance-associated macrophage protein 1 (NRAMP1) gene to pig chromosome 15. Anim. Genet. 29: 138-140. http://dx.doi.org/10.1046/j.13652052.1998.00298.x

Supek F, Supekova L, Nelson H and Nelson N (1996). A yeast manganese transporter related to the macrophage protein involved in conferring resistance to mycobacteria. Proc. Natl. Acad. Sci. USA 93: 5105-5110. http://dx.doi. org $/ 10.1073 /$ pnas. 93.10 .5105

Tanaka G, Shojima J, Matsushita I, Nagai H, et al. (2007). Pulmonary Mycobacterium avium complex infection: association with NRAMP1 polymorphisms. Eur. Respir. J. 30: 90-96. http://dx.doi.org/10.1183/09031936.00042506

Genetics and Molecular Research 16 (1): gmr16019288 
Tuggle CK, Schmitz CB and Gingerich-Feil D (1997). Rapid communication: cloning of a pig full-length natural resistance associated macrophage protein (NRAMP1) cDNA. J. Anim. Sci. 75: 277. http://dx.doi.org/10.2527/1997.751277x

Vidal SM, Pinner E, Lepage P, Gauthier S, et al. (1996). Natural resistance to intracellular infections: Nramp1 encodes a membrane phosphoglycoprotein absent in macrophages from susceptible (Nramp1 D169) mouse strains. J. Immunol. 157: 3559-3568.

Wu HM, Wang LX, Cheng DX, Ma XJ, et al. (2008). Relationship between polymorphisms of Nramp1 gene and immune function of pig. Zhongguo Nong Ye Ke Xue 41: 215-220.

Ying SC and Zhang YZ (2007). Quantitative analysis of NRAMP1 gene expression in Tibetan pigs. Journal of Sichuan University 44: 697-701.

Zhang G, Wu H, Ross CR, Minton JE, et al. (2000). Cloning of porcine NRAMP1 and its induction by lipopolysaccharide, tumor necrosis factor alpha, and interleukin-1 $\beta$ : role of CD14 and mitogen-activated protein kinases. Infect. Immun. 68: 1086-1093. http://dx.doi.org/10.1128/IAI.68.3.1086-1093.2000

Zhao SG, Cai Y, Gun SB, Yang QL, et al. (2013). Genetic polymorphisms in the swine (Sus scrofa) natural-resistanceassociated marophage protein 1 Gene (Nramp1) and their relationships with piglet diarrhea. J. Agric. Biotechnol. 21: $1351-1357$.

\section{Supplementary material}

Figure S1. 1\% agarose gel electrophoresis separation of total RNA.

Figure S2. Amplification curve (A) and melting curve (B) of qPCR analysis of Nramp1 expression in different tissues.

Genetics and Molecular Research 16 (1): gmr16019288 